\title{
Geotechnical Aspects of the Hydro-Jex Operation
}

\author{
B.F. Ulrich Knight Piésold and Co., USA
}

\begin{abstract}
Many heap leach operations are very large, covering many hectares and containing millions of tonnes of low-grade ore. Operators estimate recovery from laboratory column tests on ore samples that typically produce metal values somewhat lower than the column leach tests with the resultant metal inventory remaining in the heaps. After the ore material is placed and ripped, the only operational technique to improve recovery revolves around solution and reagent management. The key to reducing metal values in the heap inventory is to promote the contact of the leaching lixiviant to the valuable mineral and then to rinse the dissolved metal from the ore. This is normally accomplished by applying additional solution to the surface of the leach pads in a two dimensional fashion via emitters and sprinklers.

Hydro Jex, a proprietary metallurgical technique, was developed to take heap leaching into three dimensions, a new concept for the metals extractive industry. This technology has been used by Newmont Mining Corporation on gold heap leach pads on the Carlin Trend in Nevada for the last three years to recover the inventory gold remaining in heaps after traditional solution application. It is the nature of Hydro-Jex to deliver significant amounts of solution, in a controlled manner, to discrete areas within a heap. As a consequence, the resulting pore pressures an elevated phreatic surface could have a considerable and adverse influence on the slope stability of a heap. It is therefore vital that the possible effects of the HydroJex operation on slope stability be thoughtfully investigated prior to its implementation. Such investigation and analytical processes are presented herein and preliminary advice pertaining to slope stability is provided.
\end{abstract}

\section{Introduction}

In an effort to meet the challenge of thoroughly introducing the leaching solutions within the heap and then rinsing the dissolved metals from the heap, a new technology was developed by Thom Seal of Newmont Mining Corporation, and a provisional US patent on the technology has been filed. The technology is called Hydro-Jex for hydro-solution injection and metal extraction. This new technology is compatible with heap leach chemistry and recovery systems, and is currently being used at four of Newmont's heap leach pads in Nevada. The technology rights have been purchased by another mining company.

The Hydro-Jex method has been reported elsewhere (Seal, 2007) and will only be summarised herein. The technology consists of three stages:

- Drilling: The heap leach pad is drilled, sampled and assayed to quantify the metals inventory and chemistry. A typical Hydro-Jex field has drill holes which are designed and surveyed to be 50 to $60 \mathrm{~m}$ apart with depths not closer than $15 \mathrm{~m}$ above the liner to provide a safety factor against potential liner damage. The drill holes are typically designed at a prescribed distance back from the crest of the heap. A drill casing is inserted during drilling and the casing perforated at specific depths to target compact or dry zones.

- Stimulation (or fracturing): High pressure pumping of solution into the heap causes hydraulic fractures to occur in a zone around the casing (refer to Figure 1). The Hydro-Jex control trailer, linked with a high pressure pump, is positioned near the drill hole and down hole packers are inflated below and above each perforated zone. This system monitors fluid pressure and volume over time. The pump is started and pressure builds as the pump speed is increased. When the pumping pressure exceeds the earth pressure, 'breakthrough' occurs and the pressure decreases while the solution flow increases. Typical solution pumping time is 1.5 to 2 hours per zone. 
- Rinsing (or leaching): Solutions with reagents are added into the stimulated (previously fractured) zones to rinse the dissolved metal values for recovery and to further promote chemical changes. This process is illustrated in Figure 2. This phase of the operation can be completed using gravity flow to deliver solutions into the casing or, by adding pressure to the casing, greater volumes of fluid can be pumped into the heap.

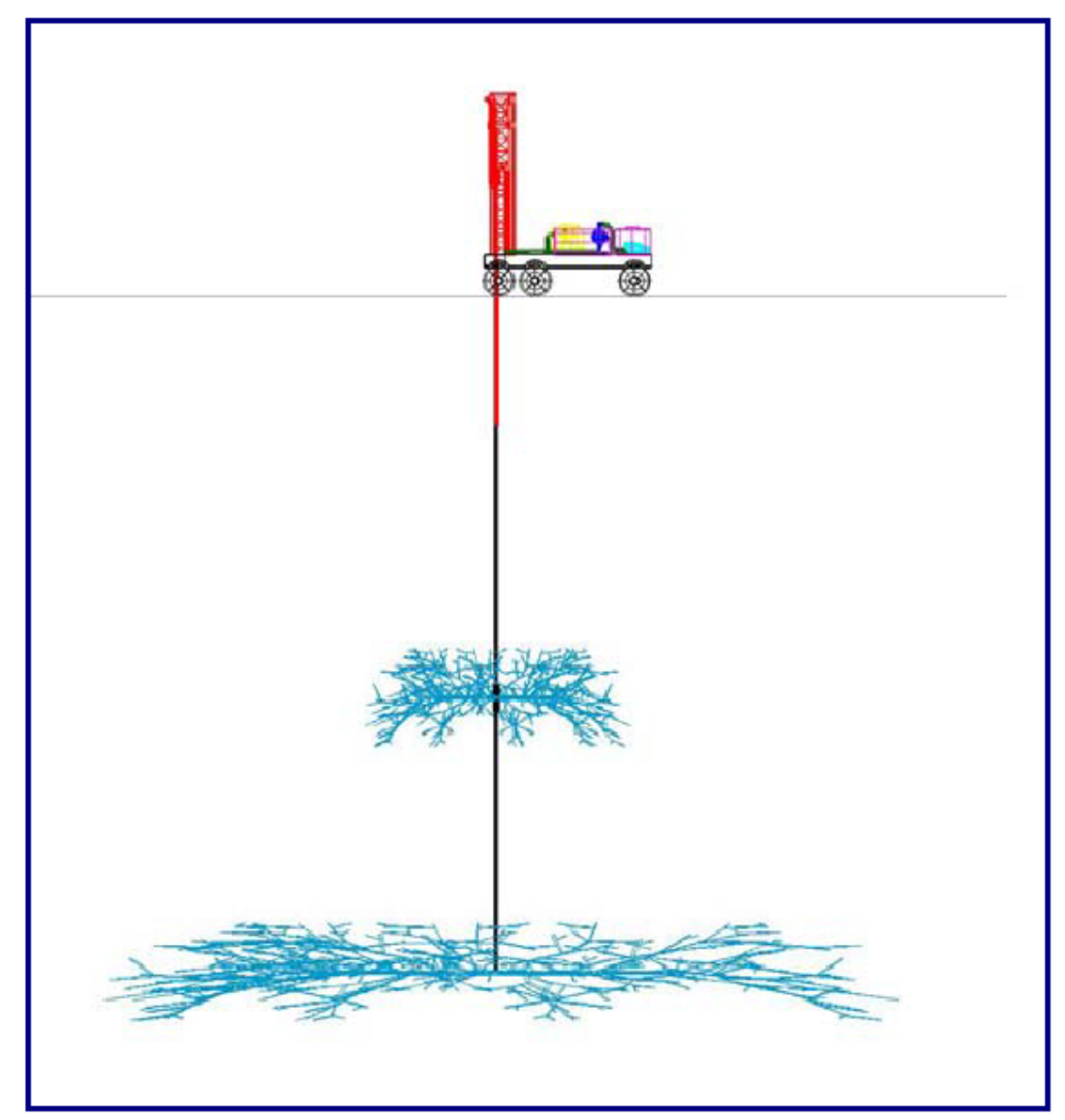

Figure 1 Idealised illustration of Hydro-Jex stimulation (Seal, 2007)

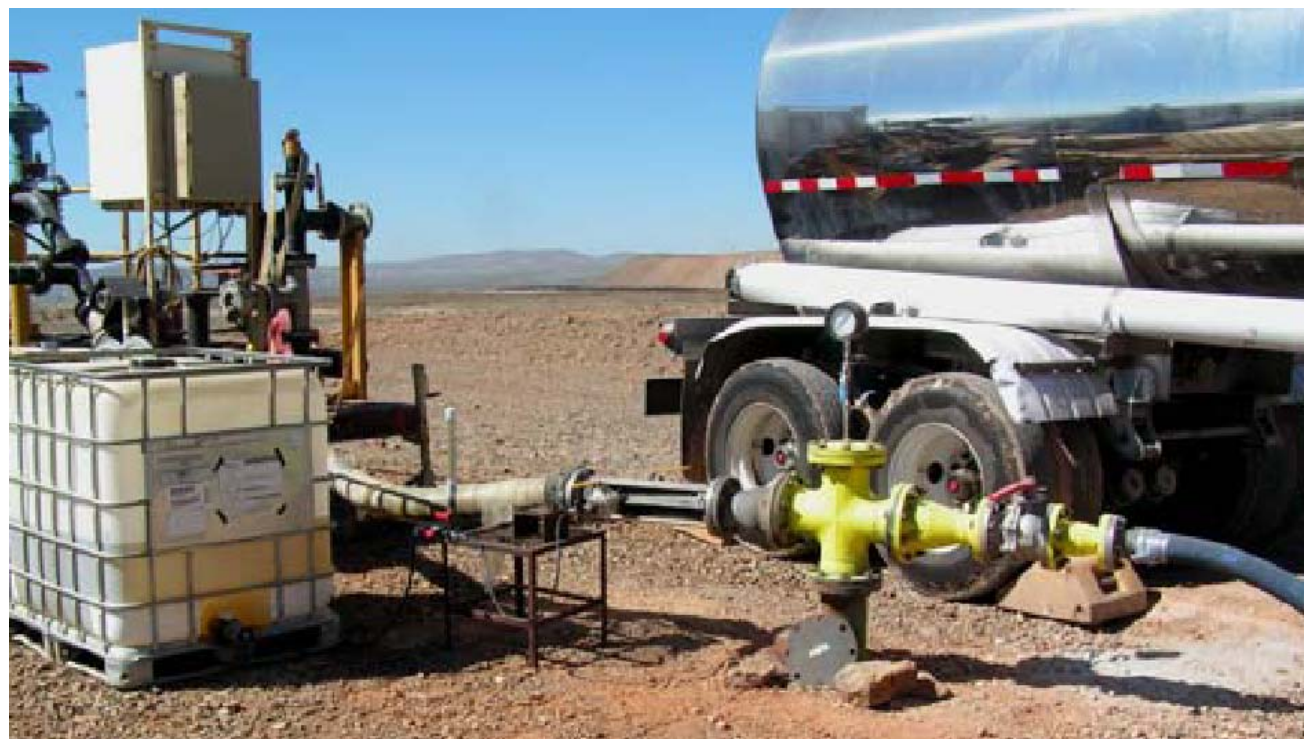

Figure 2 Rinsing process of Hydro-Jex (Seal, 2007) 


\section{Geotechnical considerations}

As stated previously, the Hydro-Jex application sequence includes drilling into the heap, installation of perforated casing, and pumping of solution at pressures high enough to create fractures and micro-fractures that allow the solution to advance into the heap at an approximately radial pattern about the casing. This injection solution often includes granular material that is left behind in the fractures when the pumping is terminated. The fractures serve as flow channels for subsequent fluids that are delivered into the casing at lower pressure.

The predominant concern of this process, as related to slope stability, is the possibility that solutions applied over a long period of time could cause a significant rise in the phreatic surface that could jeopardise the slope stability of the facility if proper precautions are not taken. A secondary but still important concern is maintaining liner integrity during both the boring and fracturing stages of the process.

The Hydro-Jex operation presents three areas that are addressed below to establish that the technique will not adversely affect the slope stability of the heap, nor the integrity of the geomembrane liner. These areas are:

- The effects of the fracturing pressure should be analysed with respect to the additional loads applied to the lining system. If a sophisticated finite element/ difference analysis were to be carried out to quantify the impact, only very little or no increase of pressure on the geomembrane would be found. This is because for there to be an increased downward force transmitted to the geomembrane there would need to be a change in mass and not just a change in forces. This can be illustrated by considering the analogy of a jacking system and scale. If the heap was resting on a scale, and a jacking system (representing the Hydro-Jex) was used to raise the heap, the heap would rise in elevation, but there would be no change in the reading on the scale, even though there is an increase in pressure within the scale. Similarly there would be no increase in pressure on the geomembrane from the Hydro-Jex fracturing operation. This is quite different to a case where a vertical downward force is added to the top of the heap. The potential impact of the added stress due to the increased fluids from the rinsing portion of the operation should be considered, possibly using a liner integrity test.

- The second consideration pertains to possible sliding of the heap caused by the near-zero effective stress (and thereby near-zero shear strength) zone induced by the Hydro-Jex operation. The HydroJex operation works on pressures that are close to the total vertical stress. When the high pressure Hydro-Jex fluids propagate radially outward from the casing, a weak plane for possible sliding is created. This case has been assessed and has been ruled out as a concern due to the resistance to sliding offered by the non-affected heap materials outside the immediate Hydro-Jex fracture zone. During the Hydro-Jex operation, geophysical surveys are made to assess the area pressurised, and the pressure can be rapidly curtailed if the fracture zone exceeds the anticipated radius of about $15 \mathrm{~m}$. As an added safety precaution, the areas along the slope nearest the active Hydro-Jex operation are cleared of equipment and personnel. Additional information on this case is provided in Section 2.1.

- The third consideration is the one that deserves the most attention; this is a case where the leaching solutions are applied at a rate that is significantly greater than the rate at which the heap material is able to dissipate the solution, and an increased phreatic surface results in the heap. If the elevated phreatic surface increases significantly, it is possible that the slope stability could be compromised. Additional information on this case is provided in the Section 2.2.

\subsection{Sliding caused by near-zero effective stress}

The potential impact of the Hydro-Jex fracturing phase on the stability of a heap has been investigated. Mathematically, the high pressure phase of the Hydro-Jex operation and its implication on heap stability may be expressed as follows:

$$
P_{h f}=\sigma_{\mathrm{t}}
$$

where $P_{h f}$ is the pressure required to cause fracturing and $\sigma_{t}$ is the total vertical overburden pressure. 
During Hydro-Jex, this creates a condition of near-zero effective stress:

$$
\begin{gathered}
\sigma^{\prime}=\sigma_{\mathrm{t}}-\mathrm{u} \\
\mathrm{u}=\mathrm{P}_{\mathrm{hf}}=\sigma_{\mathrm{t}} \\
\sigma^{\prime}=\sigma_{\mathrm{t}}-\mathrm{u}=0 \\
\sigma^{\prime}=0=\text { shear stress }
\end{gathered}
$$

where $\sigma^{\prime}$ is the effective vertical overburden pressure and $u$ is the pore pressure.

Zero effective stress $=$ zero shear stress ... no shear strength within Hydro-Jex zone during stimulation.

The potential impact on heap stability of an expanding zero effective stress zone during the high pressure portion of the Hydro-Jex operation must thus be considered. A series of slope stability analyses has been conducted to assess the possible impact of this operation. The computer programme XSTABL (Interactive Software Designs) has been used, considering static loading conditions and heap material properties that are typical for heaps. Individual angle of repose benches are shown in Figures 3 and 4. Any slopes flatter than the angle of repose would be inherently more stable.

Based on the results of this series of slope stability analyses summarised in Figures 4 and 5, it is anticipated that the high-pressure portion of the Hydro-Jex operation will not negatively affect the stability of the heap slope. During the high pressure portion of the Hydro-Jex operation, geophysical surveys will be made to assess the area pressurised, and the pressure can be rapidly curtailed if the fracture zone exceeds the anticipated radius. In addition, the areas along the slope nearest the active Hydro-Jex operation should be cleared of equipment and personnel as an added safety precaution.

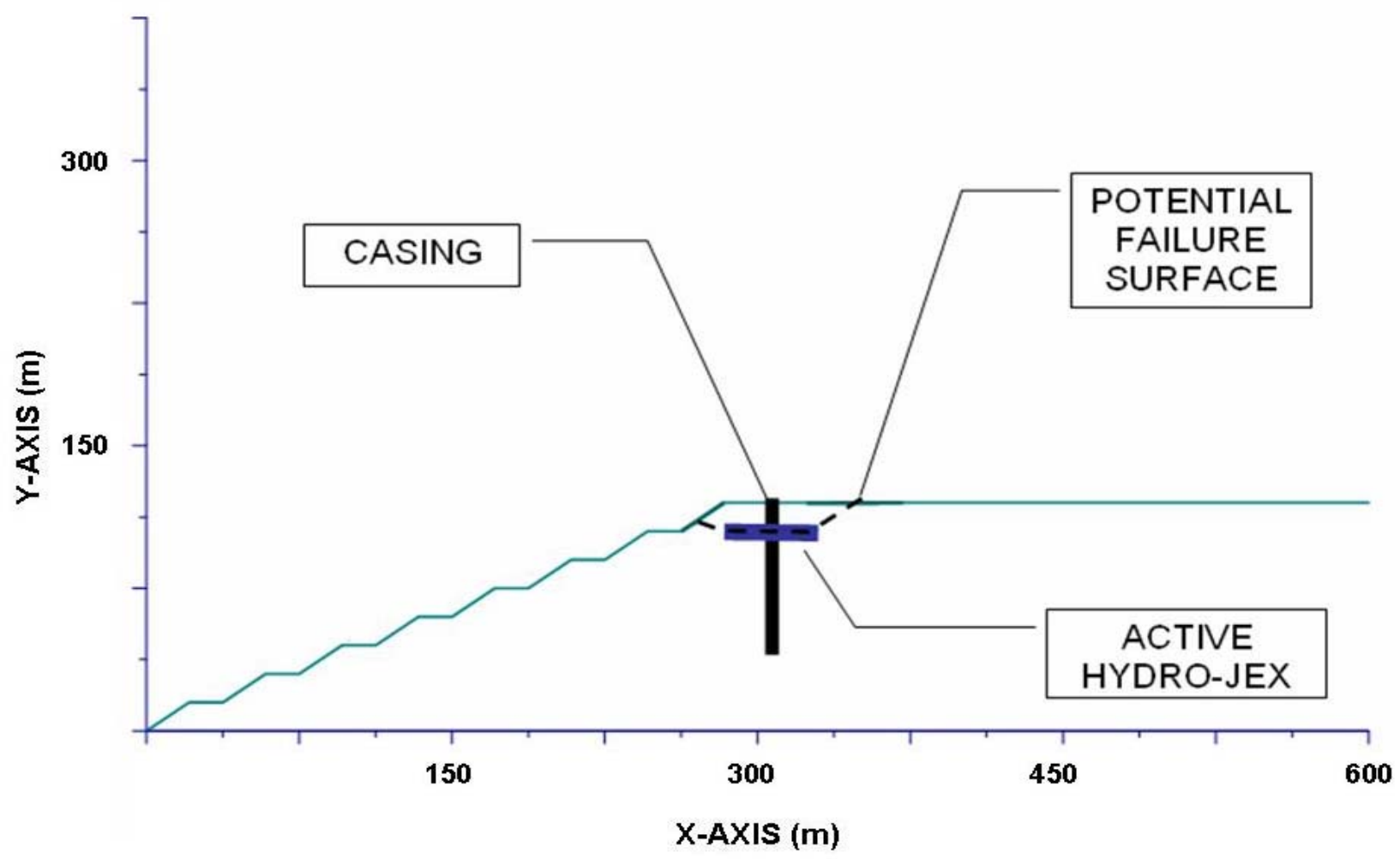

Figure 3 Basic components of the stability analysis for assessment of sliding caused by near-zero effective stress 


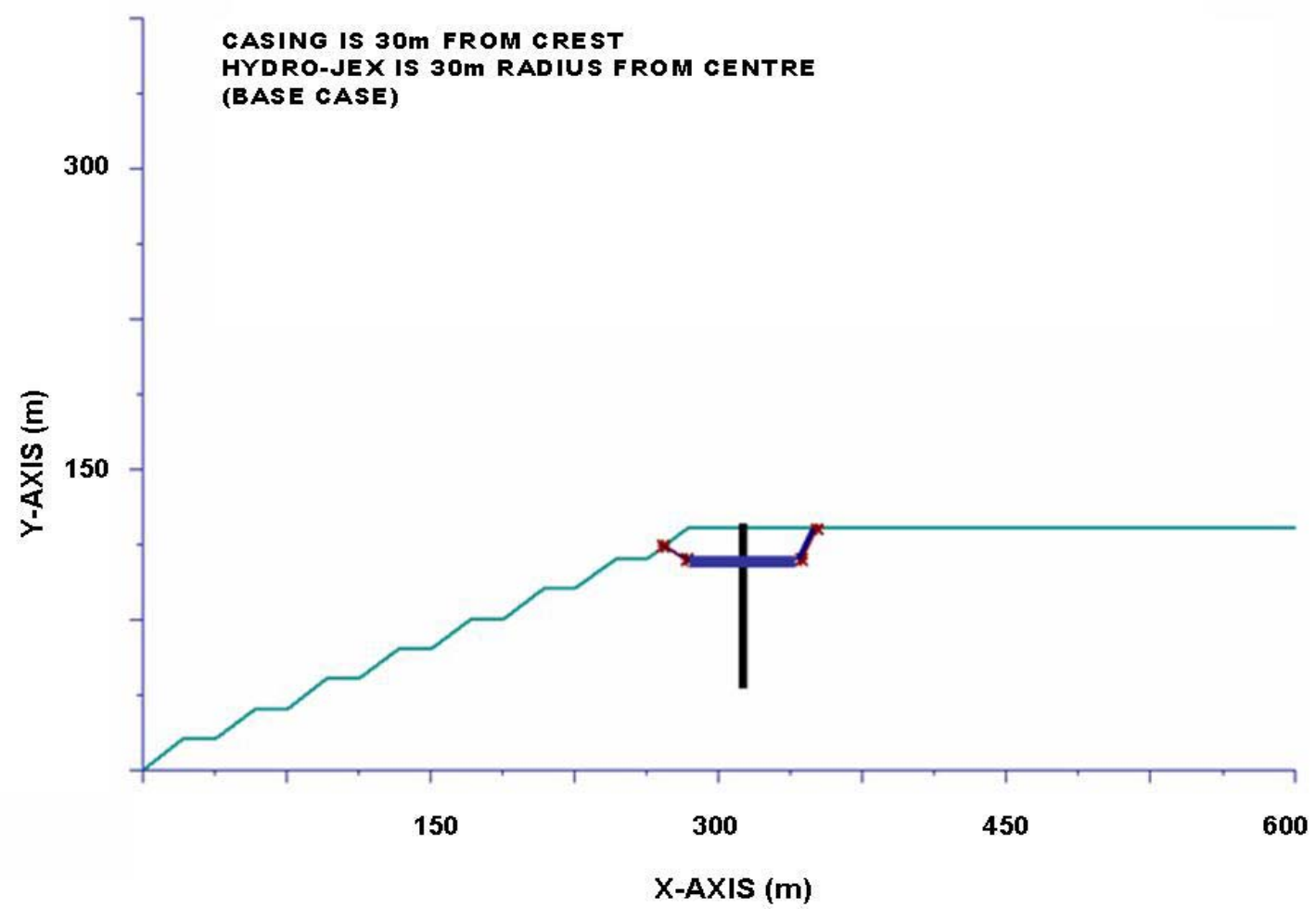

Figure 4 Illustration of the base case analysis for assessment of sliding caused by near-zero effective stress

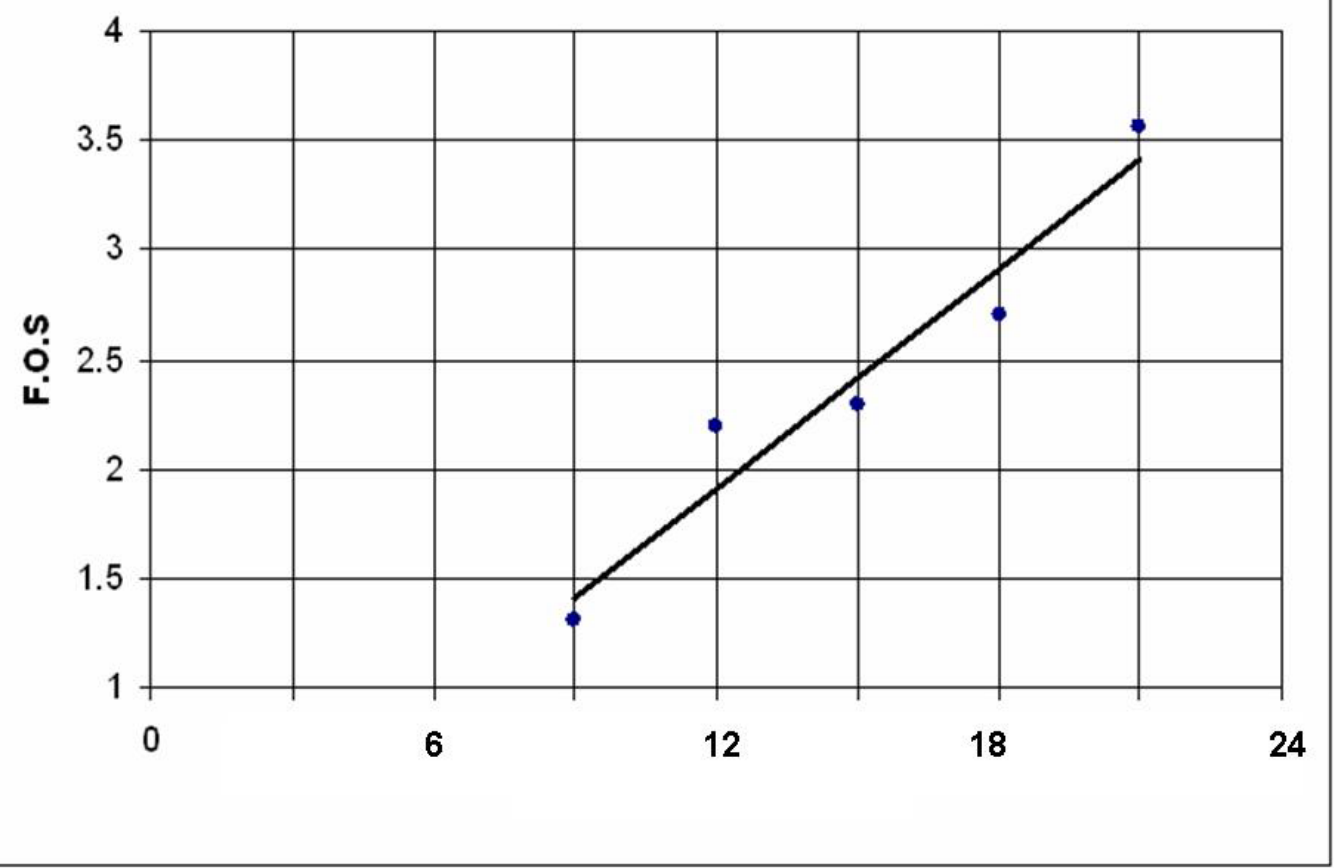

Figure 5 Summary of results for assessment of sliding caused by near-zero effective stress 


\subsection{Assessment of impacts of elevated phreatic surface}

The phreatic surface within a heap may be affected by the leaching portion of the Hydro-Jex operation, and such an impact is highly dependent upon the manner in which the solution is applied in the casing.

There are currently two main operational procedures that are being studied. At one mine, the intent is to use a packer system within the casing such that solution is only applied to a single zone within the perforated casing. The solution application zone would then be relocated to another perforated zone, or another casing, when this zone is regarded to be sufficiently leached. At another mine, the intent is to apply solution to the entire casing column such that solution may enter all the fractured zones. A much higher flow rate is associated with the second option. In both arrangements, there are several casings, and the operation would be rotated sequentially through the various casings. For both options, the leaching solutions would be delivered into the heap at a significant flow rate.

\subsection{Phreatic surface and the influence of the hydro jex operation}

The flow from the Hydro-Jex casing is a complex function of several variables including, but not limited to, the solution delivery rate, the permeability of the ore, including its saturated and unsaturated properties as well as its anisotropic characteristics, the spatial variation of the ore materials, and the presence or absence of preferential flow paths.

Another operational matter that can affect the build up of fluids within the heap is the total number of casings in which solutions are applied simultaneously, the total flow rate provided to those casings and the duration of solution application within each casing.

A reasonable first estimate of unpressurised flow regime surrounding the Hydro-Jex casing may be made based on the central assumption that the infiltration rate within the heap mass is approximately equivalent to the typical surface application rate. The merit of this assumption is based on the observation that the surface application of solutions is typically focused on creating a condition where surface puddles just begin to initiate. The maximum limit of surface solution application is maintained just at the point where the puddles start to occur, thus the application rate is approximately equivalent to the rate at which the heap can drain the fluids (not accounting for evaporation or precipitation). An unquantified error occurs since climatic factors are not accounted for.

If the typical solution delivery rate is divided by the infiltration rate, an approximate area of saturation about the casing may be established. If it is further assumed that the solution radiates from the Hydro-Jex casing in a roughly circular pattern, the diameter of the area wetted by the Hydro-Jex operation may be approximated. This, of course, disregards the presence of preferential flow paths which could reduce the area of the wetted region.

Practical experience with Hydro-Jex operations indicates that the saturated zone around the casing may be limited to a radius of about $15 \mathrm{~m}$ from the casing, as that is the observed nominal distance that the maximum hydraulic fracturing has been caused based on geophysical studies and trenching investigations. If the estimated area of the saturated zone exceeds this amount, it may be indicative that the saturated zone has a hydraulic pressure greater than the hydrostatic pressures.

Since the normal in situ pore pressures are a complex product of the material properties, fluid application practices and the effectiveness of the drainage system, it is normally suggested that a programme of material sampling and testing is carried out, followed by analytical work to approximate the pore pressure regime that may result from the Hydro-Jex operation. The results of this type of assessment are also not precise due to non-homogeneities within the heap, such as spatial variation of materials, their associated unsaturated properties and parameters, as well as undetected preferential flow paths.

\subsection{Example results}

There are a myriad of possible conditions encountered during a Hydro-Jex operation that must be considered when conducting a slope stability analysis. It is vital that these conditions are portrayed as accurately as possible in a slope stability analysis to provide the Hydro-Jex operator the maximum amount of flexibility in their procedures. A hypothetical analysis showing the possible implications of the broadening extent of a 
saturated zone is shown in Figures 6 and 7. While a stable situation is still predicted here, that is largely based on the high factor of safety associated with the pre-Hydro-Jex heap; the reduction in the safety factor is significant.

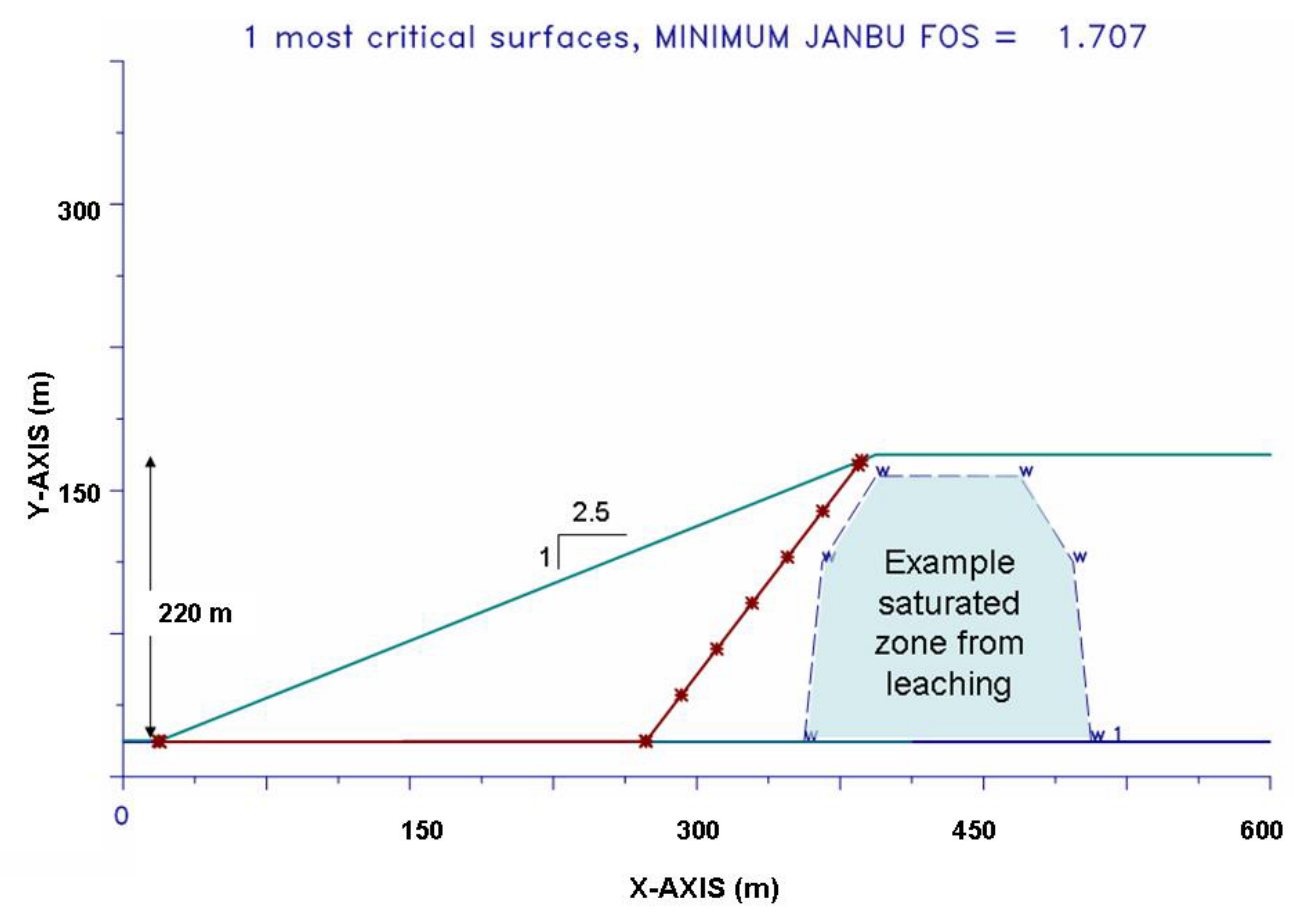

Figure 6 Example slope stability result with an elevated phreatic surface owing to Hydro-Jex operation

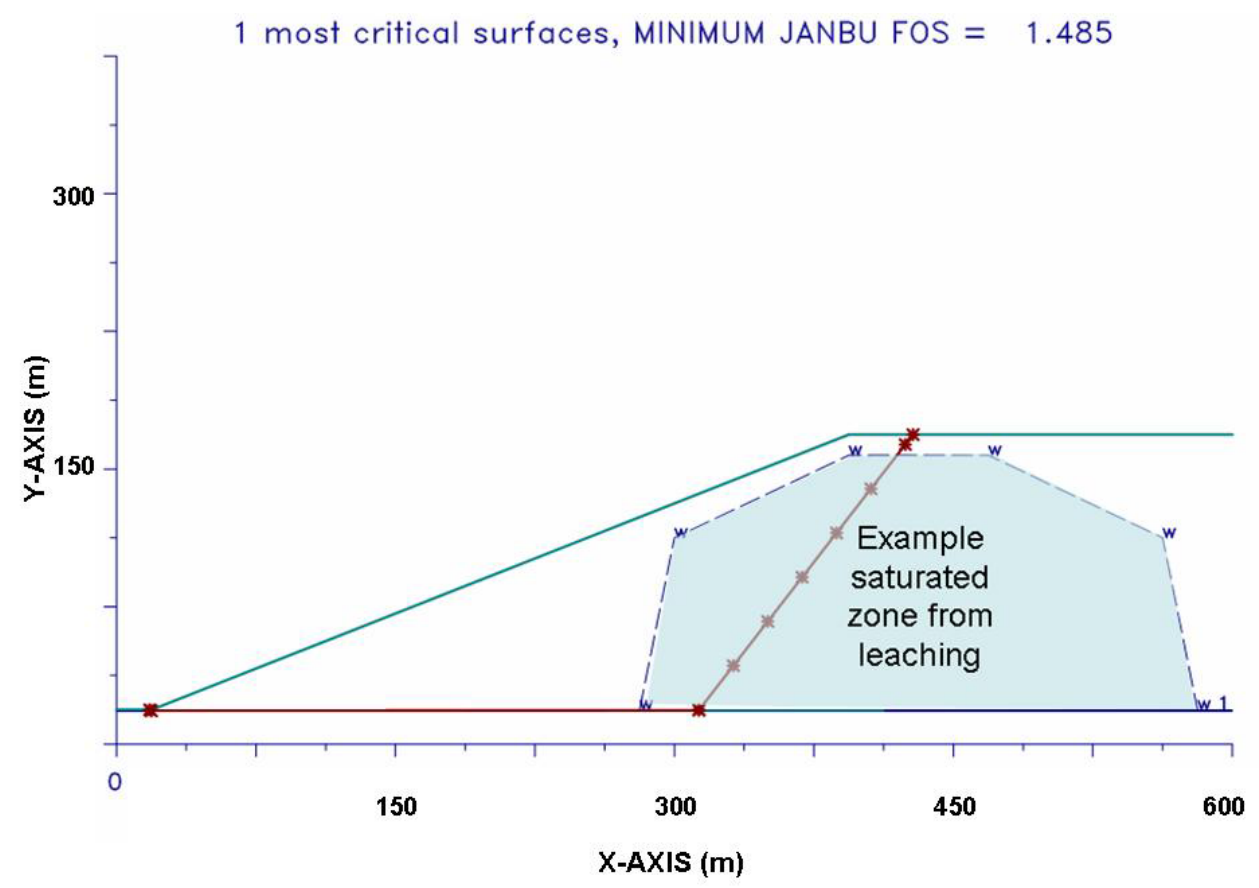

Figure 7 Example slope stability result with an enlarged phreatic surface owing to Hydro-Jex operation 
Figure 8 depicts a trial result for a heap that has been regraded. Hydro-Jex operations are scheduled for the interior portions of the heap. Based on the operational parameters and constraints recommended for that operation, an acceptable factor of safety is predicted for this heap. Acceptable stability is maintained in this case because the elevated phreatic surface is well away from the toe of the slope, and there is a sufficient buttressing effect provided by the unaffected materials nearer the toe of the slope.

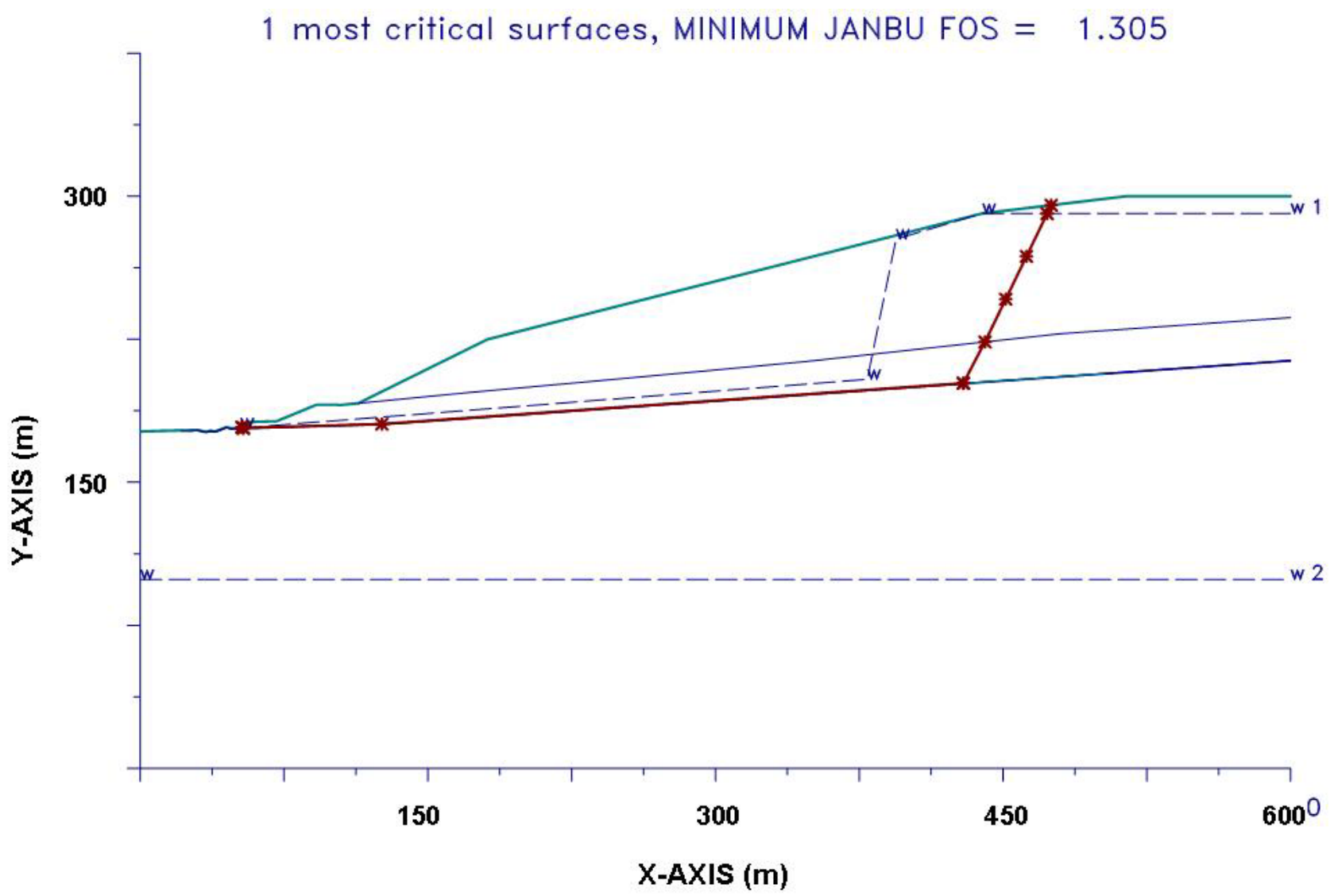

Figure 8 Example slope stability result for a regraded heap

\section{Conclusions and recommendations}

Even under the conditions imposed by a Hydro-Jex operation, stable slope conditions can be achieved in heap leach facilities if proper care and analysis are undertaken.

During the Hydro-Jex operation a geophysical contractor should be on site to provide information on solution migration during the start-up of the Hydro-Jex operation. This can greatly improve the confidence level when transitioning from the analytical realm to the operational realm.

Until there is sufficient operational information to dictate otherwise, the delivery of leaching solutions in a Hydro-Jex casing should not be carried out until the standing solution level in the casing is determined. The current operational guidelines indicate that solution should not be applied to the casing if standing solution is found at an elevation higher than the lowest level of perforations in that casing. As a preliminary operational parameter, solution levels should be monitored in all casings within a radius less than $100 \mathrm{~m}$ from the casing actively being fed leaching solution. If the solution level rises in any of these nearby casing, the solution application should be halted, and moved to another casing (other than the casing where the solution level was noted to be on the rise).

An improved method of operating the Hydro-Jex system would involve a non-sequential progression to avoid the creation and sustaining of localised solution-doming in the heap. By this, it is meant that the operation should not proceed in a sequential manner, from north to south, left to right, in a circular pattern or any other manner that causes adjacent casings to be operated in succession to one another. 
Once operational experiences are gained, these recommendations should be reviewed and adjusted as required in order to maintain a safe, stable facility.

\section{Acknowledgements}

The author would like to thank Thom Seal, Newmont Mining Corp., Inc. Seal's previous work was relied upon heavily in writing this paper.

\section{References}

Seal, T. (2007) Hydro-Jex: Heap Leach Pad Stimulation Technology; Ready for World Wide Industrial Adoption? SME Annual Meeting, Denver, Colorado, 25-28 February, Preprint, pp. 7-123.

XSTABL, Interactive Software Designs, Inc, 953 N. Cleveland Street, Moscow, ID 83843, U.S.A. 